\title{
PART II: REFLECTIONS Career Development Patterns and Needs
}

of Faculty

Thoughtful, effective programming for faculty and institutional development depends on an understanding of faculty as individuals, but this understanding must be conditioned by a knowledge of faculty roles, the contexts in which faculty work, and the forces at work in their career development. However, as our first paper points out, assumptions about faculty career patterns based on "generic" research on adult development have not been subjected to rigorous empirical testing. The author, Mary Pat Mann, notes limitations of existing research on faculty career development and points out the dangers of uncritical acceptance of frequently-cited stage models.

The remaining papers in this section illustrate different approaches to the problem of specifying faculty needs in relation to career development stages. Sandy Barber identifies faculty needs deductively, based on analysis of the academic "guild" system and institutional context. Turner and Boice focus on new faculty, and identify their needs empirically. Finally, Supapidhayakul and Simpson use methods of phenomenological investigation to explore experiences of faculty who change careers but remain within their original institutions. These papers provide a basis for revised, clarified understanding of faculty needs, enabling us to rethink our potential contributions to their career development. 